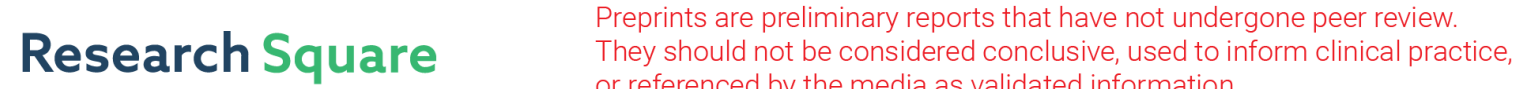 or referenced by the media as validated information. \\ Different Pulsed Radiofrequency Modes on Gasserian Ganglion Improved Acute/subacute Zoster-related Trigeminal neuralgia: A Randomized, Double-Blinded, Controlled Trial
}

\section{Cheng-fu Wan}

The First Affiliated Hospital of China Medical University

Tao Song ( $\sim$ songtaocmu@163.com )

The First Affiliated Hospital of China Medical University https://orcid.org/0000-0002-9915-9673

\section{Research article}

Keywords: Pulsed radiofrequency, zoster-related trigeminal neuralgia, visual analog scale, 36-item Short Form health survey

Posted Date: November 19th, 2020

DOl: https://doi.org/10.21203/rs.3.rs-108532/v1

License: (c) (1) This work is licensed under a Creative Commons Attribution 4.0 International License. Read Full License 


\section{Abstract}

Background: Trigeminal postherpetic neuralgia (PHN), developed from herpes zoster virus infected on gasserian ganglion, is a severe neuropathic pain and often refractory to existing treatment. Pulsed radiofrequency (PRF) is known to be effective for treating acute/subacute zoster-related pain, but the effectiveness of different PRF mode has not been tested.

Objective: This study aimed to investigate the efficacy and safety of different PRF modes on gasserian ganglion in patients with acute/subacute zoster-related trigeminal neuralgia.

Methods: 120 patients were equally randomized into 2 groups $(n=60)$ : high-voltage, long-duration PRF(HL-PRF) group and standard PRF(S-PRF) group. One cycle high-voltage, long-duration PRF was applied in HL-PRF group and three cycles standard PRF were performed in S-PRF group. Visual analog scales (VAS), 36-item short form health survey scores (SF-36) and average doses of pregabalin were recorded at different time points.

Results: There were significant declined in VAS and SF-36 scores in both two groups at different time point after PRF treatment $(P<0.001)$. The scores of VAS and SF-36 in HL-PRF group were significantly lower than those in S-PRF group at different time points after treatment $(P<0.05)$. The dosages of pregabalin were also lower in HL-PRF group at days 3,14 and 28 after treatment $(P<0.05)$. There was no serious adverse effect in either group.

Conclusion: High-voltage, long-duration PRF on gasserian ganglion is more effective than standard PRF for acute/subacute zoster-related trigeminal neuralgia patients.

Clinical Trial Registration: ChiCTR2000038775

\section{Background}

Herpes zoster $(\mathrm{HZ})$ is caused by the reactivation of varicella-zoster virus after being latent in the sensory ganglia(1,2). Postherpetic neuralgia (PHN) is the most common and severe syndrome resulted from $\mathrm{HZ}$, manifesting as a persistent spontaneous, knife-like pain or paroxysmal burning that seriously affects a patient's quality of life(3). $\mathrm{HZ}$ infection of the trigeminal nerve is a high risk factor for trigeminal PHN(4) and patients often suffered more severe facial pain with a poor quality of life $(5,6)$.

Several risk factors, such as older age, severe acute pain, severe rash, immunocompromised etc, were associated with higher risk to develop from $\mathrm{HZ}$ to $\mathrm{PHN}(7,8)$. The mechanism of trigeminal PHN was multiple $(9,10)$, thus there was no effective treatments to cure trigeminal PHN $(11)$. Therefore, it is essential to avoid the transition from acute/subacute $\mathrm{HZ}$ pain to $\mathrm{PHN}$, and this prevention strategy is in line with international perception concerning chronic pain management $(12,13)$.

Pulsed radiofrequency (PRF) is a novel therapeutic strategy that has recently been used(14) by pain practitioners as a non- or minimally neurodestructive technique. PRF is delivered in a pulse of 20 
milliseconds ( $\mathrm{ms}$ ) followed by a silent period of $480 \mathrm{~ms}$ to avoid radiofrequency heat lesions(15). Previous researches demonstrate that standard mode PRF was an effective therapies for treating PHN(16-18), thus our studies have confirmed that high-voltage, long-duration PRF on ganglions represented an effective and safe method for PHN patients $(19,20)$. Nevertheless, it is still not clear that which mode of PRF could get better pain relief. Hence, the aim of this study was to compare the clinical effect of two modes in treating acute/subacute zoster-related trigeminal neuralgia.

\section{Methods}

\section{Study Participants}

In accordance with the ethical principles of the Declaration of Helsinki, the current study was designed as a prospective, randomized controlled clinical trial conducted from February 14, 2019 to March 31, 2020. The study protocol was approved by the Human Ethics Committee of the First Affiliated Hospital of China Medical University (No: 2018 - 308). Informed consent forms were signed by all patients. This trial was registered with chictr.org.cn (number ChiCTR2000038775). Consent forms were signed by all patients.

\section{Inclusion Criteria}

(1) Patients were older than 60 years. (2) Trigeminal HZ course less than 3 months and conservative treatment, such as antiepileptic medicine, antidepressants, opioids, or physical treatments, according to the international association for the study of pain guidelines(21), was ineffective. (3) Skin lesions had healed, but there was still persistent, intense and intractable pain, local skin hyperalgesia, numbness, and sensory abnormalities. (4) Visual analog scale (VAS) score $\geq 5$ points in 24 hours.

\section{Exclusion Criteria}

(1) Patients were intolerance to the study procedures, coagulation disorders or applied anticoagulant, uncooperative behavior (i.e., the patient did not provide an immediate response). (2) Patients suffered severe liver and kidney dysfunction or severe cardiopulmonary disease. (3) Drug abuse. (4) Patients were intellectual inability to complete the self-evaluation questionnaires [VAS and 36-item Short Form health survey (SF-36)].

\section{Randomization and Sequence Generation}

157 patients were initially enrolled, but 37 patients had to be excluded for this study (19 patients not meeting inclusion criteria, 10 patients declined to participate and 8 patients for other reasons). Therefore, 120 patients were finally enrolled and randomly assigned by means of a computer-generated random allocation sequence into two groups: high-voltage, long-duration PRF(HL-PRF) group in which one cycle high-voltage, long-duration for 900 seconds PRF was applied was applied $(n=60)$ and standard PRF(SPRF) group in which three cycles standard PRF for 120 seconds were performed $(n=60)$ (Fig. 1).

\section{Description of PRF}


All patients were treated in the supine position and received $2 \mathrm{~L} /$ minute of oxygen through nasal catheter. Heart rate, respiratory rate and oxygen saturation ( $\mathrm{SaO} 2)$ were monitored continuously during the treatment.

Computed tomography (CT) was used to determine the route of percutaneous insertion. The insertion point was marked on the skin of the cheek. After sterilization and local anesthesia with $0.5 \%$ lidocaine, a 20-G insulated needle (14.5 cm, with a 10-mm active tip, Baylis Medical Company) was inserted and slowly advanced toward the foramen ovale along the designated path. When the depth of the needle reached the predefined depth, a new CT scan was performed to confirm the proper location of the needle tip. After the tip of needle puncture through the site of the foramen ovale no more than 1.0 centimeter. The electrical stimulation was performed to assure coverage of affected area: (1) sensory [50 Hz], 0.1$0.3 \mathrm{~V}$, to induce paresthesia in the herpes area. (2) motor [2 Hz] $0.3-0.5 \mathrm{~V}$, jaw tremor will be induced when V3 division is affected. The needle tip was adjusted slowly until the sensation and movement determined that the affected area was completely covered and other normal areas were avoided to cover (Fig. 2).

After the gasserian ganglion were attained, PRF treatment was performed using the Pain Management Generator (PM-230, Baylis Medical Company, Montreal, Canada). In HL-PRF group, PRF treatment was initiated with following parameters: $42^{\circ} \mathrm{C}, 2 \mathrm{~Hz}, 20 \mathrm{~ms}$ pulses in a 1-second cycle, and 900 seconds duration time. The initial voltage output was $40 \mathrm{~V}$, which was then gradually increased until the patients could not tolerate the abnormal sensations (i.e., burning pain). The maximal voltage output ranged from 60 to $100 \mathrm{~V}$ according to the patient's individual tolerance until the 900 -seconds PRF treatment was terminated. In S-PRF group, PRF treatment was as following settings: $42^{\circ} \mathrm{C}, 2 \mathrm{~Hz}, 20$ ms pulses in a 1second cycle, and 120 seconds duration time. Three cycles were performed as auto standard mode (Fig. 3).

\section{Blinding}

The surgical and PRF procedures were only performed by the same investigator (Dr. 1) and others did not know which PRF mode was chosen. All follow-ups were performed by another investigator ( $\operatorname{Dr} 2$ and $\mathrm{Dr}$ 3). The instrument was operated by a nurse (Nurse 1) of our pain management center. The two mode PRF were applied to two groups. The nurse did not participate in any other therapeutic and follow-up activities, or trial discussions.

\section{Drug administration}

All the patients were treated with pregabalin if the patient suffered severe pain after treatment. The other medication treatments were avoided to be used. The dosage was increased or reduced according to the alteration of the pain severity.

\section{Primary Outcome}


The VAS scores were evaluated before treatment and in the morning on days 3,7 , and 14 , and months 1 , 3 and 6 after treatment.

\section{Secondary outcomes}

\section{SF-36 Score Evaluation}

The SF-36 health survey $(13,22)$ was used to assess the health of the PHN patients. Patients needed only 6-9 minutes to complete the test. It assesses nearly all conceptual domains of the substantially longer generic patient-based assessments (PBAs), which have been used in other studies (23). The scores, including bodily pain, general health, mental health, physical function, physical role, role-emotional, social function and vitality, were also evaluated before treatment and on days 7 , and months 1,3 , and 6 after treatment.

\section{Average dosage of rescue medication $(\mathrm{mg} / \mathrm{d})$}

The initial oral dose of pregabalin was $50 \mathrm{mg}$ every 12 hours. We could gradually increase the dose in the event of the VAS scores were $\geq 3$ or when the frequency of acute pain flares was more than 6 times per day. The average dosages of pregabalin $(\mathrm{mg} / \mathrm{d})$ were collected on days $1,3,7,14$, and 28 after the treatment in two groups.

\section{Side Effects}

Any side effects, including bleeding at the puncture site, infection, intracranial hemorrhage and other adverse reactions, were recorded at days 1,3 and 7 after treatment.

\section{Statistical analysis}

\section{Sample Size}

According to our previous study(24), the effective rate of semilunar ganglion adjustment in the test group was about $90 \%$, and the effective rate in the positive control group was about $52 \%$, so the difference between the effective rates in the 2 groups was $38 \%$. Based on this information, Thus, we determined that a sample size of at least 28 in each group would enable us to detect a significant difference with a power of 0.8 and a type-l error of 0.05 . We estimated the potential maximal dropout rates as $5 \%$, thus set the final sample size of 120 .

\section{Data analysis}

Numeric variables are expressed as mean \pm standard deviation (SD) values and the number of observations. The normal distribution of the continuous variables was tested using the KolmogorovSmirnov test and all measurements fell in normal distribution. Values are expressed as mean and 95\% confidence interval $(\mathrm{Cl})$. Categorical variables were tested using Fisher's exact test. Statistical analysis 
was performed using the Statistical Package for Social Sciences version 19.0 (SPSS Inc., Chicago, IL, USA). A p value $<0.05$ was considered to be statistically significant.

\section{Results}

\section{Patient Demographics}

There was no significant difference in demographic characteristics, such as ages, gender, weights, disease duration and pain scores, in the two groups (Table 1). 1 patient in HL-PRF group was survived less than 6 months; 2 patients in HL-PRF group and 2 patients in S-PRF group were dropped out during follow-ups, so we will eliminate their experimental data (Fig. 1).

\section{VAS}

There was no significant difference in mean VAS scores before treatment in two groups. After treatment, there were significant declined in both two groups at different time point $\left({ }^{*} \mathrm{P}<0.001\right.$; Fig. 4). But VAS scores were significantly declined at day 4, 7 and months 3, 6 after treatment in HL-PRF group compared to S-PRF group( ${ }^{\#} \mathrm{P}<0.05$; Fig. 4).

\section{SF-36}

There was no significant difference in baseline of SF-36 scores before treatment in two groups, but the scores of bodily pain, general health, mental health, physical function, physical role, role-emotional, social function and vitality were significantly improved at different time point after treatment in both two groups $\left({ }^{*} \mathrm{P}<0.01\right.$; Fig. 5). Thus the scores of all other than role-emotional and vitality could be significantly improved at some time points after treatment in HL-PRF group compared to S-PRF group ${ }^{\#} P<0.05$; Fig. 5).

\section{Rescue drug dosage $(\mathrm{mg} / \mathrm{d})$}

The rescue drug (pregabalin) dosage administration was lower in HL-PRF group than those in S-PRF group at days 3,14 and 28 after treatment (*P<0.05; Fig. 6 ).

\section{Side Effects}

No patient was withdrawn the test duo to any adverse reaction. After treatment, there was no bleeding at puncture site, infection, intracranial hemorrhage, or any other serious adverse effect in two groups. 7 patients in S-PRF group and 11 patients in HL-PRF group suffered ecchymoma on face; however, they rapidly recovered without adverse effects during the follow-up period.

\section{Discussion}

PRF on Gasserian ganglion not only effectively relieved pain, but also significantly improved the quality of life for patients with acute/subacute zoster-related trigeminal neuralgia in this study. Our results also demonstrated that high-voltage, long-duration PRF mode provides better analgesic effect and 
improvement of life quality than standard mode. No significant difference was observed in other adverse reactions between the two groups.

$\mathrm{PHN}$ is a severe pain syndrome that develop from re-activation of the herpes zoster virus. With the damage caused by the virus, cell dehydration, decreased cell number, chronic inflammatory cell infiltration and other pathological changes may occur in the primary sensory neurons, which lead to neuropathic pain (25). PHN appears spontaneously, and is accompanied by allodynia, and hyperalgesia in damaged area(26). The etiology and mechanism of PHN remains not completely clear, hence there are no definite effective therapeutic drug or treatment for these patients(27-30).

The fifth cranial nerve, called the trigeminal nerve, is the dominate facial and orofacial sensory nerve. The virus dormant in gasserian ganglion can reactivate and replicate when the body immune system weakens at any point(31). Compared to PHN in other areas of the body, trigeminal herpes zoster pain has a high probability of developing into $\mathrm{PHN}(32)$ and is more difficult to get well pain relief with drugs and nerve blocks treatment. Therefore, it is an essential strategy to treat acute/subacute episodes of HZ-associated pain as early as possible to avoid the further development to PHN.

With a discontinuous pulse current (20 ms, 2HZ), PRF is a minimally invasive treatment(33) and acts as a kind of neuromodulation to exert long-term analgesic effects(34). Previous studies have reported some microdamages in axons (abnormal morphology of membrane and mitochondria, injury and disintegration of microfilaments and microtubules), and the higher extent of damage in C fibers compared to A- $\delta$ after PRF treatment on peripheral nerves(35). Both clinical and basic research have suggested that PRF could be used to treat neuropathic pain. In some studies patients got better analgesic effect after PRF on gasserian ganglion(36), hence we chose gasserian ganglion as therapeutic target in this study.

We have confirmed that high-voltage, long-duration PRF mode on gasserian ganglion was an effective and safe method for acute/subacute zoster-related trigeminal neuralgia in our previous studies(20). In that study, the therapeutic voltage was gradually increased from $40 \mathrm{~V}$ to a maximum level according to the patient's individual level of tolerance. Every patient was treated with individualized voltage-dose and obtained better therapeutic effect. Thus in other studies(36,37), standard PRF mode on gasserian ganglion was applied to patients. All the patients were treated with same voltage-dose and obtained better therapeutic effect as well. However, the question is that does these two PRF mode get same therapeutic effect? This clinical trial was designed to verify this question.

Patients received high-voltage, long-duration PRF for 900 seconds in HL-PRF group but patients were administered standard PRF for 120 seconds in 3 cycles in S-PRF group. Other treatment parameters except voltage were the same in two groups. We found that the patients in both two groups obtained significantly decreased VAS scores after treatment $(P<0.001)$ and experienced significantly improved quality of life $(\mathrm{P}<0.001)$. The comparison of VAS scores showed that there was a significantly declined at day 4, 7 and months 3,6 after treatment in HL-PRF group compared to S-PRF group $(P<0.05)$. The SF36 scores of body pain, general health, mental health, physical function, physical role and social function could be significantly improved at some time points after treatment in HL-PRF group compared to 
another group $(\mathrm{P}<0.05)$. The dosage of pregabalin administered was also significant lower in HL-PRF group compared to S-PRF group at days 3,14 and 28 after treatment $(P<0.05)$. Therefore, we considered that high-voltage, long-duration PRF could get better therapeutic effect for acute/subacute zoster-related trigeminal neuralgia. There might be the following reasons: 1. Patients in HL-PRF group obtained longterm neuromodulation on gasserian ganglion than those in S-PRF group. 2. Higher output voltage and electrical field intensity might be another reason for better analgesic effect.

Nevertheless, there were several limitations in our current study design, which should be addressed in future trials. First, the patients were recruited from a single center, and the sample size was relatively small. Second, the patients were only followed for 6 months after treatment. Future studies should include a large, prospective study across multiple centers and a longer length of follow up.

\section{Conclusion}

In summary, high-voltage, long-duration PRF mode on gasserian ganglion could get better therapeutic effect for acute/subacute zoster-related trigeminal neuralgia compared to standard PRF mode. There was no difference in security for the two PRF modes.

\section{Declarations}

\section{Author contribution}

Cheng-Fu Wan: clinical experimental design, clinical trial practice; statistical analysis of data and manuscript writing;

Tao Song: clinical experimental design and manuscript review.

\section{Acknowledgements}

We would like to thank all the patients, doctors and nurses involved in the current study.

\section{Conflict of Interest}

The authors declare that they have no conflict of interests.

\section{Funding statement}

This manuscript was is supported by Liaoning Province Education Department (NO. QNZR2020007).

\section{Data availability statement}

The data used and/or analyzed during the current study are available from the corresponding author on reasonable request. 


\section{Ethical approval}

This prospective randomized controlled clinical trial was approved by the Ethics Committee of the First Affiliated Hospital of China Medical University (No: 2018-308) and registered at chictr.org.cn with the number of ChiCTR2000038775. All procedures performed in studies involving human participants were in accordance with the ethics standards of the institutional and national research committee and with the 1964 Helsinki Declaration and its later amendments or comparable ethics standards.

\section{References}

1. Sampathkumar P DL, Martin DP. Herpes zoster (shingles) and postherpetic neuralgia. Mayo Clinic proceedings 2009:84: 274-280.

2. Gershon AA GM, Breuer J, Levin MJ, Oaklander AL, Griffiths PD. Advances in the understanding of the pathogenesis and epidemiology of herpes zoster. J Clin Virol 2010:48 Suppl 1: S2-7.

3. Fashner J, Bell, A. L. Herpes zoster and postherpetic neuralgia: prevention and management. Am Fam Phys 2011:83: 1432-1437.

4. Nalamachu S, Morley-Forster, P. Diagnosing and managing postherpetic neuralgia. Drugs Aging 2012:29: 863-869.

5. Bouhassira D CO, Gaillat J, Hanslik T, Launay O, Mann C, Rabaud C, Rogeaux O, Strady C. Patient perspective on herpes zoster and its complications: An observational prospective study in patients aged over 50 years in general practice. Pain 2012:153: 342-349.

6. Doth AH HP, Jensen MP, Taylor RS. The burden of neuropathic pain: A systematic review and metaanalysis of health utilities. Pain 2010:149: 338-344.

7. Forbes HJ TS, Smeeth L, Clayton T, Farmer R, Bhaskaran K, Langan SM. A systematic review and meta-analysis of risk factors for postherpetic neuralgia. Pain 2016:157: 30-54.

8. Kawai K RE, Tsai TF, Cheong HJ, Dhitavat J, Covarrubias AO, Yang L, Cashat-Cruz M, Monsanto H, Johnson K, Sampalis JS, Acosta CJ. Predictors of postherpetic neuralgia in patients with herpes zoster: a pooled analysis of prospective cohort studies from North and Latin America and Asia. Int J Infect Dis 2015:34: 126-131.

9. Schlereth T HA, Breimhorst M, Fechir M, Kern U, Magerl W, Birklein F. Association between pain, central sensitization and anxiety in postherpetic neuralgia. European journal of pain (London, England) 2015:19: 193-201.

10. Johnson RW RA. Clinical practice. Postherpetic neuralgia. The New England journal of medicine 2014:371: 1526-1533.

11. Shannon HJ AJ, Damle JS. Evidence for interventional procedures as an adjunct therapy in the treatment of shingles pain. Advances in skin \& wound care 2012:25: 276-284.

12. Gewandter JS DR, Turk DC, Farrar JT, Fillingim RB, Gilron I, Markman JD, Oaklander AL, Polydefkis MJ, Raja SN, Robinson JP, Woolf CJ, Ziegler D, Ashburn MA, Burke LB, Cowan P, George SZ, Goli V, Graff OX, lyengar S, Jay GW, Katz J, Kehlet H, Kitt RA, Kopecky EA, Malamut R, McDermott MP, 
Palmer P, Rappaport BA, Rauschkolb C, Steigerwald I, Tobias J, Walco GA. Research design considerations for chronic pain prevention clinical trials: IMMPACT recommendations. Pain 2015:156: 1184-1197.

13. Dong DS YX, Wan CF, Liu Y, Zhao L, Xi Q, Cui WY, Wang QS, Song T. Efficacy of Short-Term Spinal Cord Stimulation in Acute/Subacute Zoster-Related Pain: A Retrospective Study. Pain physician 2017:20(5): E633-E645.

14. Van Boxem K HM, Van Zundert J, Patijn J, van Kleef M, Joosten EA. Pulsed radiofrequency: A review of the basic science as applied to the pathophysiology of radicular pain: A call for clinical translation. Regional anesthesia and pain medicine 2014:39: 149-159.

15. Cosman ER J, Cosman ER, Sr. Electric and thermal field effects in tissue around radiofrequency electrodes. Pain Medicine (Malden, Mass) 2005:6: 405-424.

16. Ke M YF, Yi J, Xeuhua H, Xiaoming L, Zhijun C, Chao H, Yingwei W. Efficacy of pulsed radiofrequency in the treatment of thoracic postherpetic neuralgia from the angulus costae: A randomized, doubleblinded, controlled trial. Pain physician 2014:16: 15-25.

17. Kim ED LY, Park HJ. Comparison of efficacy of continuous epidural block and pulsed radiofrequency to the dorsal root ganglion for management of pain persisting beyond the acute phase of herpes zoster. PLoS One 2017::12(8): e0183559.

18. Steven P Cohen BLP, Larry Fulton, Edward T Neely, Connie Kurihara, Anita Gupta, Jimmy Mali, Diana C Fu, Michael B Jacobs, Anthony R Plunkett, Aubrey J Verdun, Milan P Stojanovic, Steven Hanling, Octav Constantinescu, Ronald L White, Brian C McLean, Paul F Pasquina, Zirong Zhao. Randomized, double-blind, comparative-effectiveness study comparing pulsed radiofrequency to steroid injections for occipital neuralgia or migraine with occipital nerve tenderness. Pain 2015:156(12): 2585-2594.

19. Cheng-fu Wan YL, Dao-song Dong, Lin Zhao, Qi Xi, Xue Yu, Wen-yao Cui, Qiu-shi Wang, Tao Song. Bipolar High-Voltage, Long-Duration Pulsed Radiofrequency Improves Pain Relief in Postherpetic Neuralgia. Pain physician 2016:19: E721-E728.

20. Wan CF DD, Song T. High-Voltage, Long-Duration Pulsed Radiofrequency on Gasserian Ganglion Improves Acute/Subacute Zoster-Related Trigeminal Neuralgia: A Randomized, Double-Blinded, Controlled Trial. Pain physician 2019 Jul;:22(4): 361-368.

21. E. C. Ethical guidelines for pain research in humans. Committee on Ethical Issues of the International Association for the Study of Pain. Pain 1995:63: 277-278.

22. Keller SD MT, Kosinski M, Ware JE. Jr. Monitoring health outcomes among patients with arthritis using the SF-36 Health Survey: Overview. Medical care 1999:37: Ms1-9.

23. Stacey BR GR. Use of gabapentin for postherpetic neuralgia: Results of two randomized, placebocontrolled studies. Clinical therapeutics 2003:25: 2597-2608.

24. Wan C DD, Song T. High-Voltage, Long-Duration Pulsed Radiofrequency on Gasserian Ganglion Improves Acute/Subacute Zoster-Related Trigeminal Neuralgia: A Randomized, Double-Blinded, Controlled Trial. Pain Physician 2019:22(4): 361-368. 
25. Reichelt M ZL, Arvin AM. Mechanisms of varicella-zoster virus neuropathogenesis in human dorsal root ganglia. J Viro/ 2008:82: 3971-3983.

26. Ding Y LH, Hong T, Zhao R, Yao P1, Zhao G. Efficacy and Safety of Computed Tomography-Guided Pulsed Radiofrequency Modulation of Thoracic Dorsal Root Ganglion on Herpes Zoster Neuralgia. Neuromodulation 2018 Oct 4.

27. GM. S. Unmet need in the treatment of postherpetic neuralgia. Am J Manag Care 2013:19: S207-213.

28. Finnerup NB AN, Haroutounian S, McNicol E, Baron R, Dworkin RH, Gilron I, Haanpaa M, Hansson P, Jensen TS, Kamerman PR, Lund K, Moore A, Raja SN, Rice AS, Rowbotham M, Sena E, Siddall P, Smith BH, Wallace M. . Pharmacotherapy for neuropathic pain in adults: a systematic review and meta-analysis. Lancet Neurol 2015:14: 162-173.

29. Kumar V KK, Mathieu A. Neuraxial and sympathetic blocks in herpes zoster and postherpetic neuralgia: an appraisal of current evidence. Reg Anesth Pain Med 2004:29: 454-461.

30. SK. T. Management of herpes zoster and postherpetic neuralgia. J Am Acad Dermatol 2007:57: S136-142:: S136-142.

31. Stinson C, Deng, M., Yee, M. B., Bellinger, L. L., Kinchington, P. R., and Kramer, P. R. Sex differences underlying orofacial varicella zoster associated pain in rats. BMC Neurol 2017:17: 95.

32. Nagasako EM, Johnson, R. W., Griffin, D. R., and Dworkin, R. H. Rash severity in herpes zoster: correlates and relationship to postherpetic neuralgia. J Am Acad Dermatol 2002:46: 834-839.

33. Yu Shi WW. Treatment of Neuropathic Pain Using Pulsed Radiofrequency: A Meta-analysis Pain Physician 2016:19(7): 429-444.

34. Perret DM KD, Li KW, Sinavsky K, Newcomb RL, Miller JM, Luo ZD. Application of pulsed radiofrequency currents to rat dorsal root ganglia modulates nerve injury-induced tactile allodynia. Anesthesia and analgesia 2011:113.

35. Erdine S BA, Cosman ER, Cosman ER Jr. Ultrastructural changes in axons following exposure to pulsedradiofrequency fields. Pain practice : the official journal of World Institute of Pain 2009:9: 407417.

36. Arıcı T KM, Kılıç E, Erhan E. Radiofrequency thermocoagulation combined with pulsed radiofrequency for gasserian ganglion blockage. Agri 2018:30(4): 179-182.

37. Yuanyuan Ding TH, Hongxi Li, Peng Yao, Guangyi Zhao. Efficacy of CT Guided Pulsed Radiofrequency Treatment for Trigeminal Postherpetic Neuralgia. Front Neurosci 2019, Jul:13: 708. doi: $710.3389 /$ fnins.

\section{Table}




\section{Table 1.}

Baseline characteristics of the participants (mean \pm SD)

\begin{tabular}{|lll|}
\hline Patients & S-PRF group & HL-PRF group \\
& $\mathrm{n}=60$ & $\mathrm{n}=60$ \\
& $($ completed 58) & (completed 57) \\
\hline Age (years) & $67.37 \pm 18.35$ & $65.01 \pm 15.28$ \\
& $(67.96 \pm 18.66)$ & $(65.54 \pm 16.02)$ \\
\hline Female/male, $\mathrm{n}$ & $22 / 26$ & $25 / 23$ \\
\hline Weight (kg) & $(20 / 26)$ & $(23 / 22)$ \\
\hline disease duration(days) & $60.88 \pm 19.21$ & $56.95 \pm 21.72$ \\
& $69.36 \pm 11.23$ & $67.98 \pm 12.98$ \\
& $(68.19 \pm 10.67)$ & $(67.64 \pm 12.47)$ \\
\hline Average pain scores & $7.53 \pm 2.68$ & $(57.28 \pm 19.64)$ \\
\hline & $(7.61 \pm 2.49)$ & $(7.39 \pm 2.43)$ \\
\hline
\end{tabular}

\section{Figures}




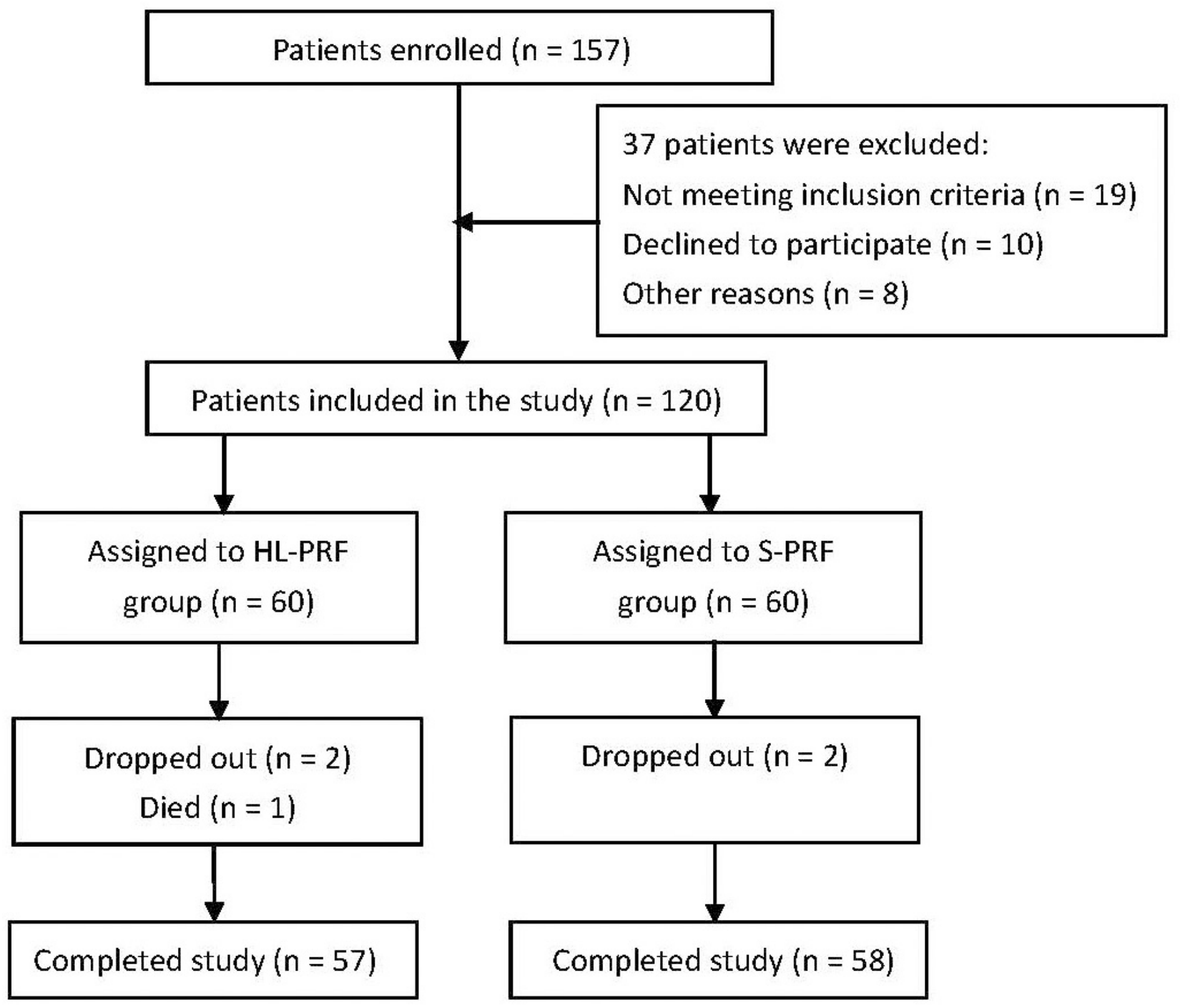

Figure 1

Flowchart showing assignment of 120 patients randomized patients to 2 groups. 


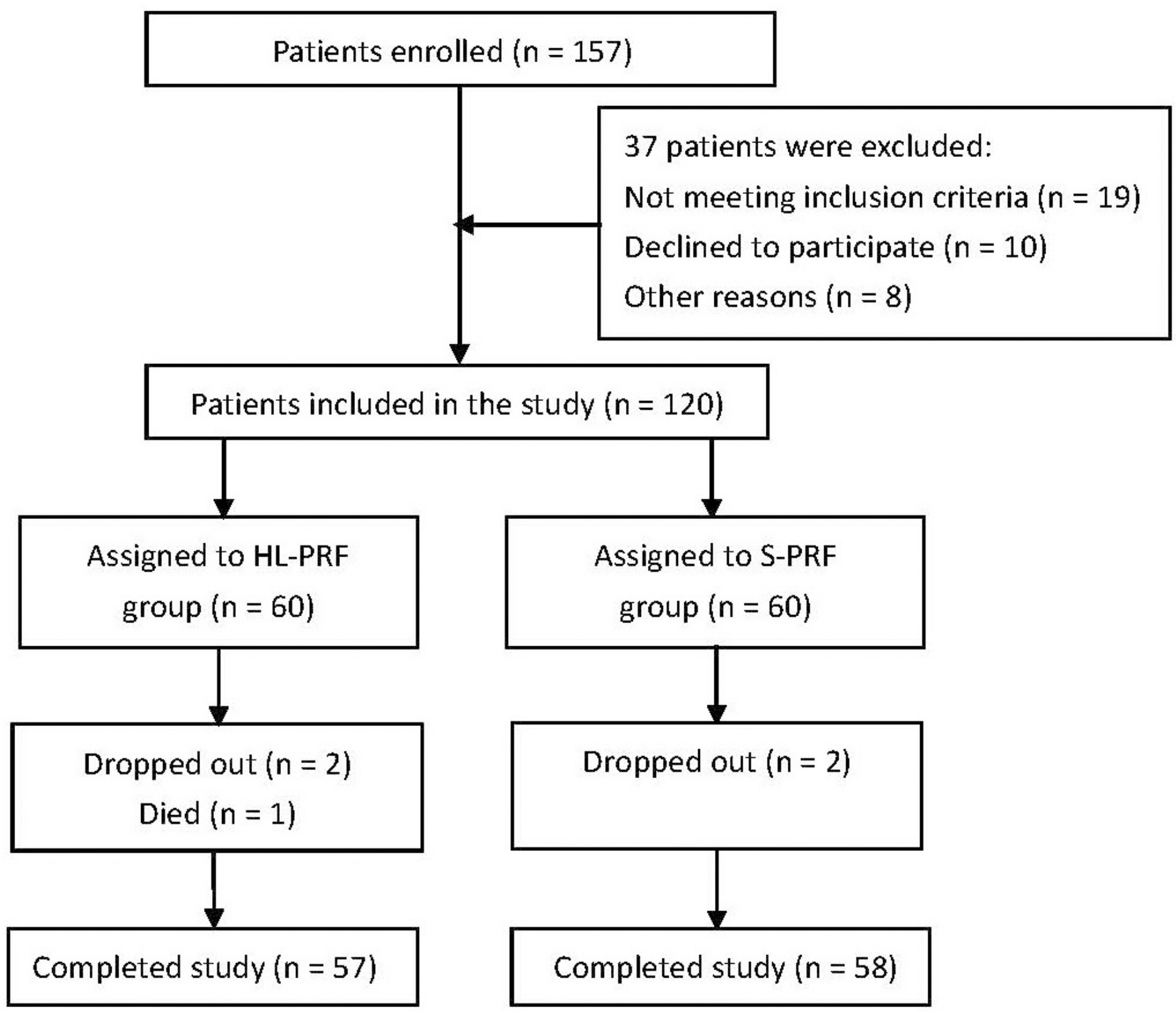

Figure 1

Flowchart showing assignment of 120 patients randomized patients to 2 groups. 


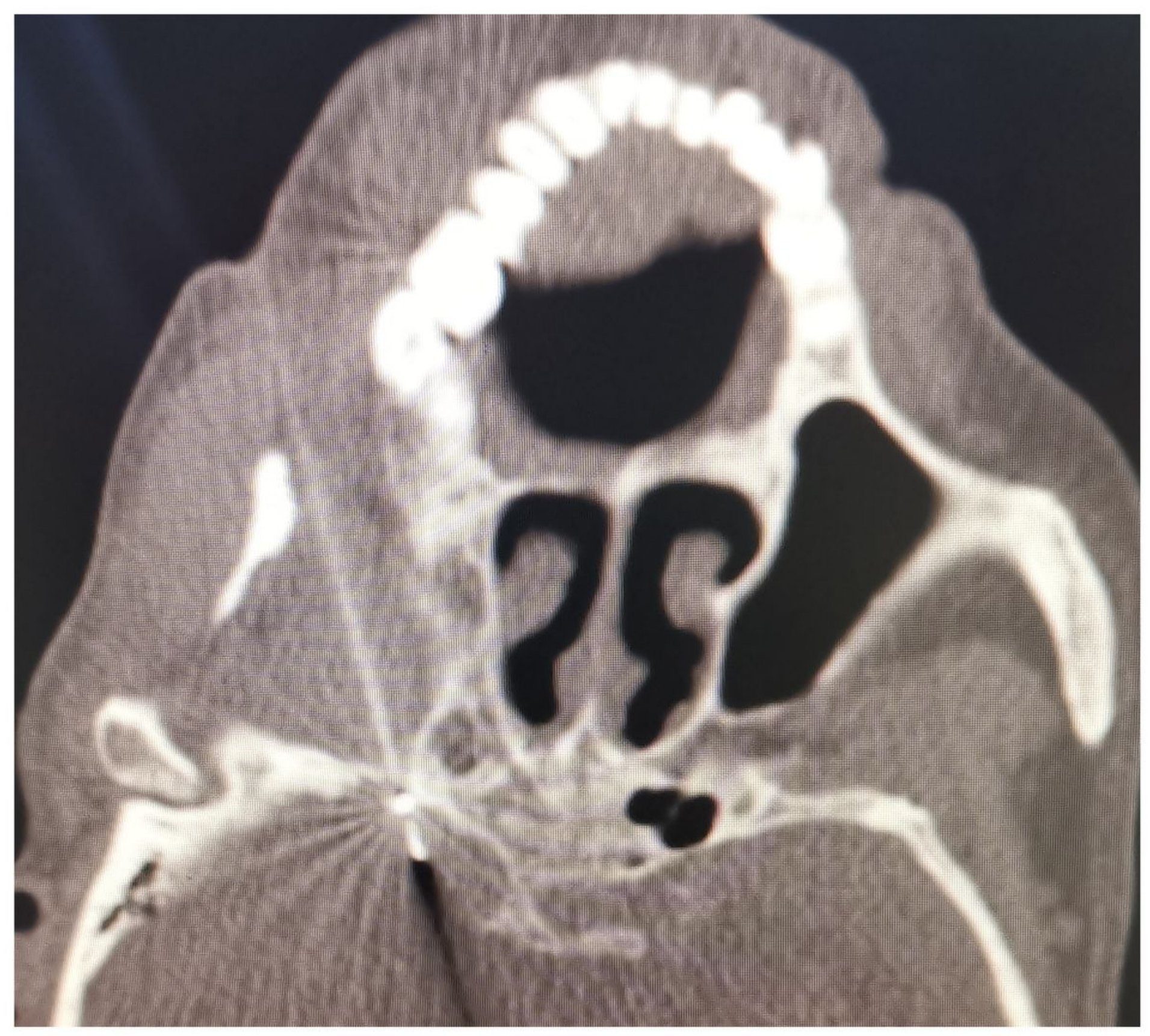

Figure 2

Representative CT image of the electrode needle puncturing arrives gasserian ganglion. 


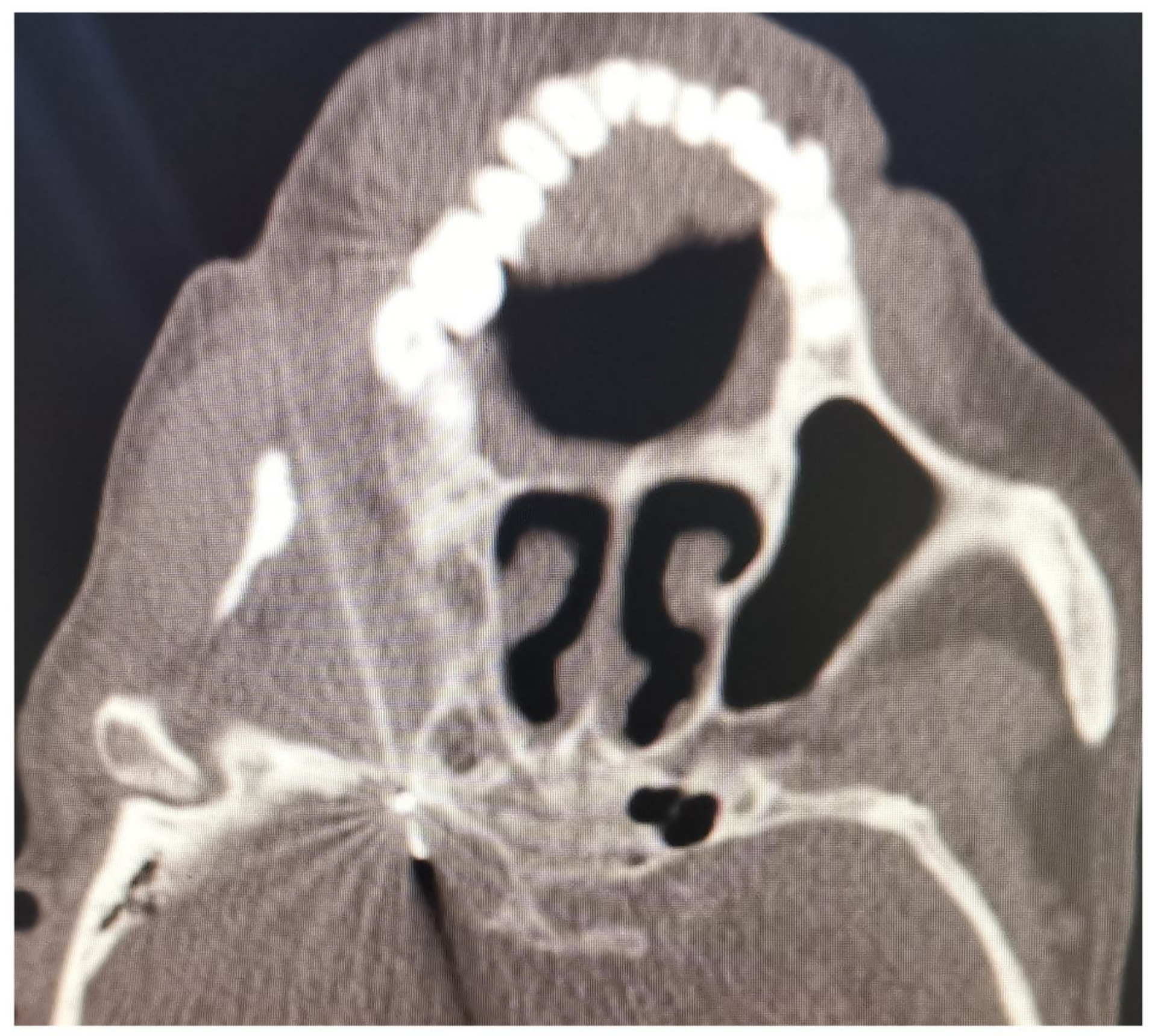

Figure 2

Representative CT image of the electrode needle puncturing arrives gasserian ganglion. 

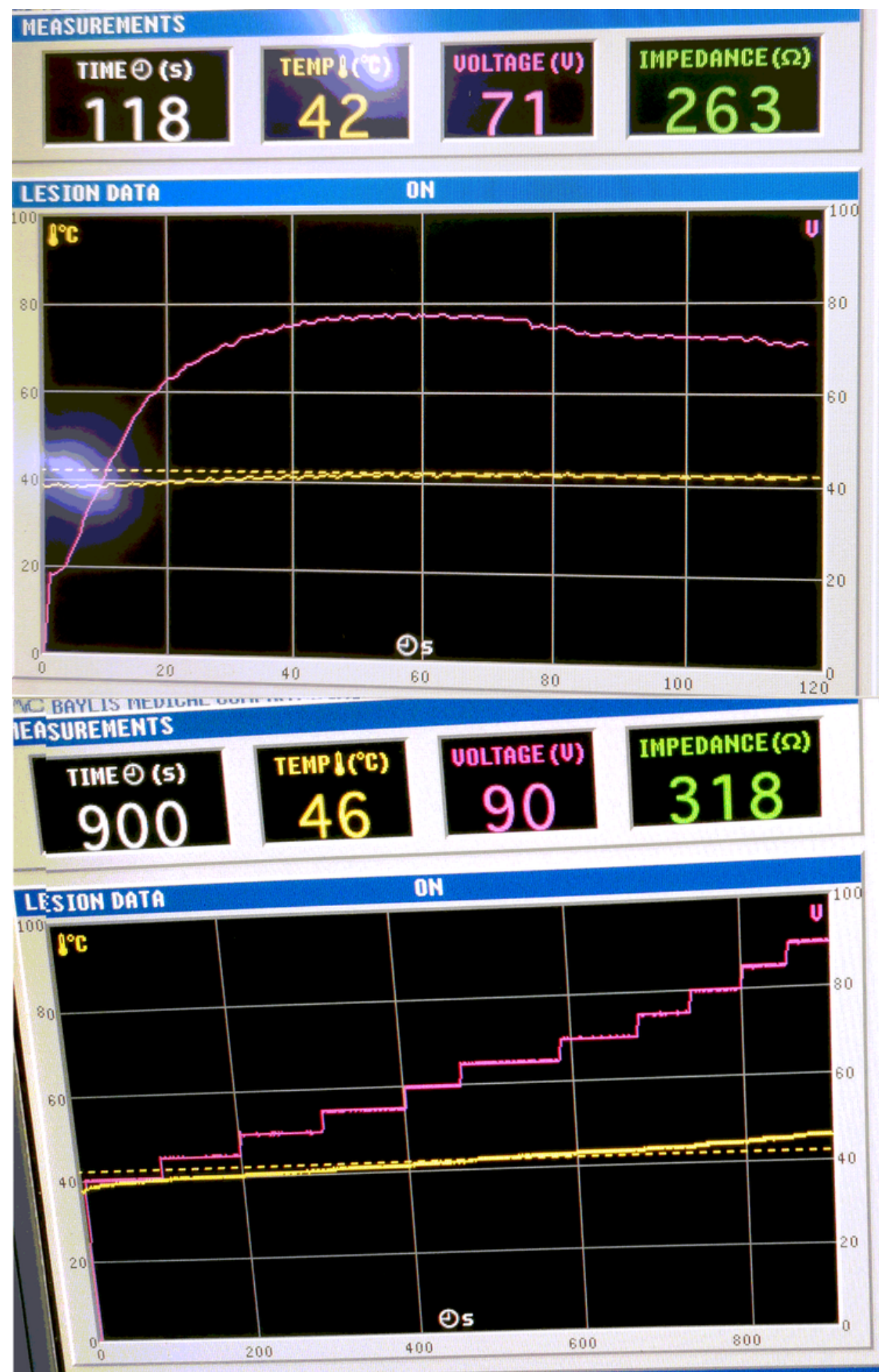

STIMULATION MODE
LESION MODE
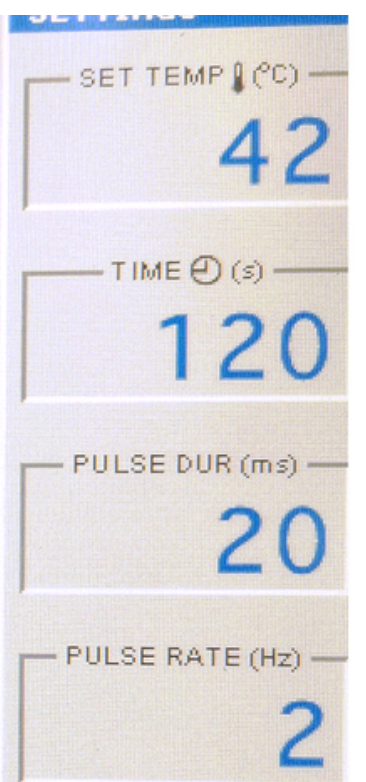

S-PRF

Group

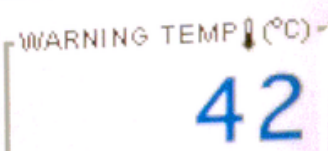

TIME $\odot(s)$

\section{HL-PRF}

Group

- PULSE RATE $(\mathrm{Hz})$ -

2

90

Figure 3

Representative image of two different PRF mode. 

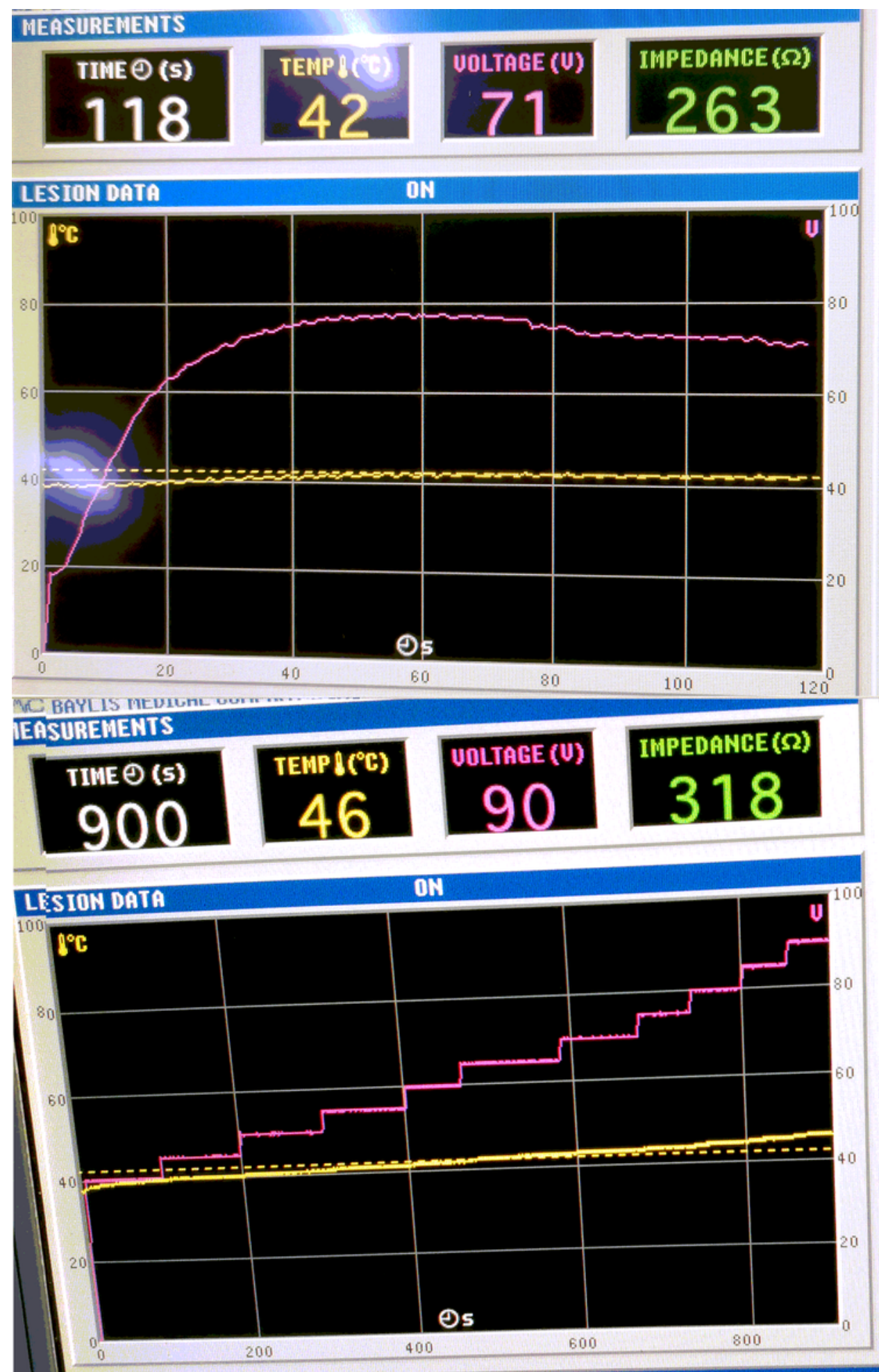

STIMULATION MODE
LESION MODE
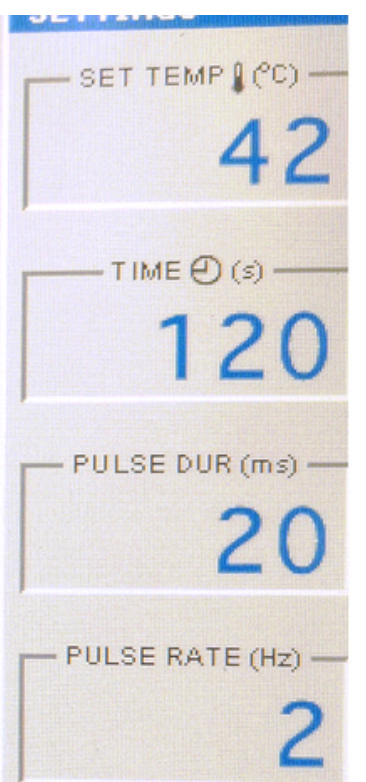

S-PRF

Group

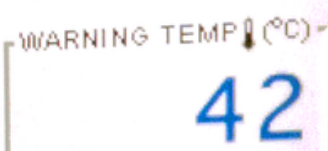

TIME $\odot(s)$

\section{HL-PRF}

Group

- PULSE RATE $(\mathrm{Hz})$ -

2

90

Figure 3

Representative image of two different PRF mode. 


\section{Changes in VAS}

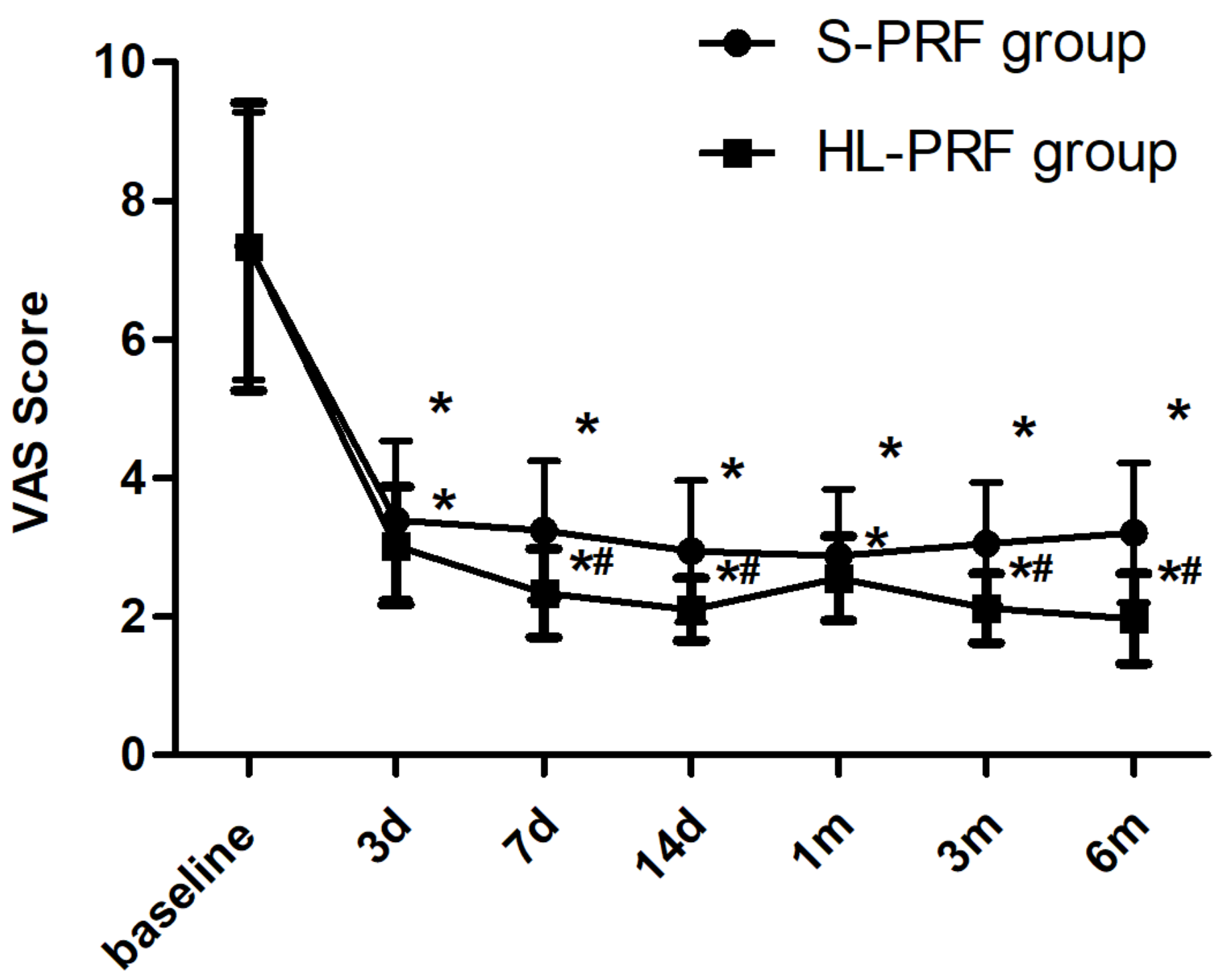

Figure 4

Significantly decreased mean visual analogue scale (VAS) scores after treatment ${ }^{*} p<0.001$ indicates Pre VAS vs. Post VAS. \#p<0.05 indicates HL-PRF group vs. S-PRF group. 


\section{Changes in VAS}

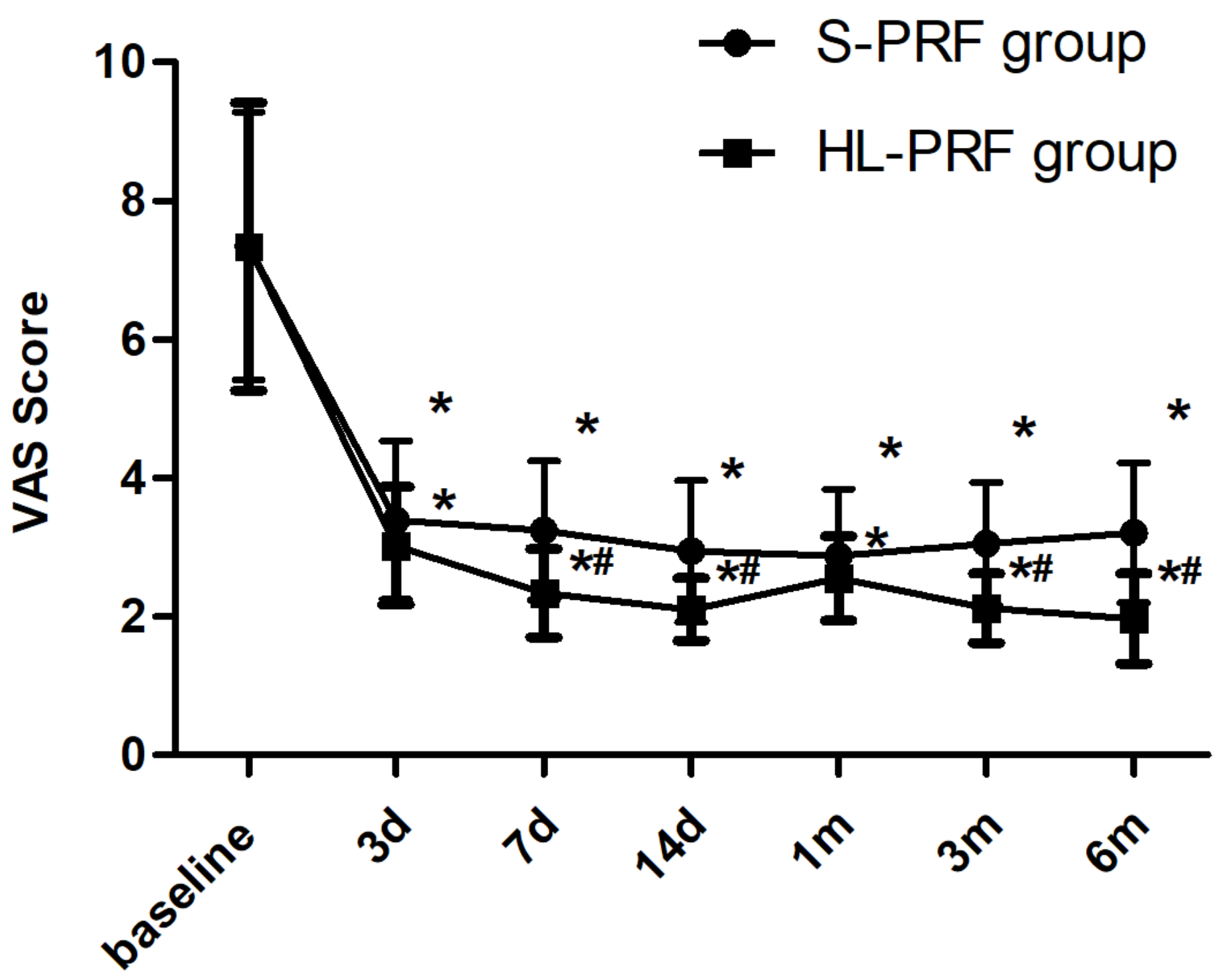

Figure 4

Significantly decreased mean visual analogue scale (VAS) scores after treatment ${ }^{*} p<0.001$ indicates Pre VAS vs. Post VAS. \#p<0.05 indicates HL-PRF group vs. S-PRF group. 


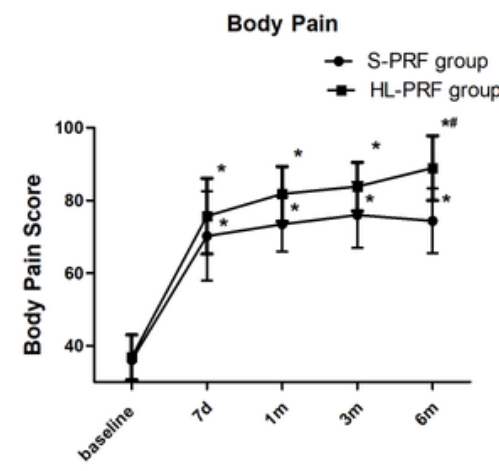

Mental Health

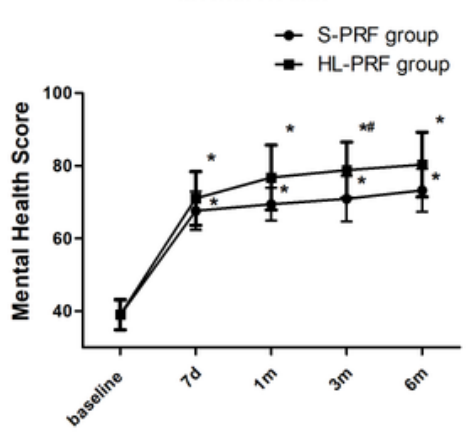

Physical Role

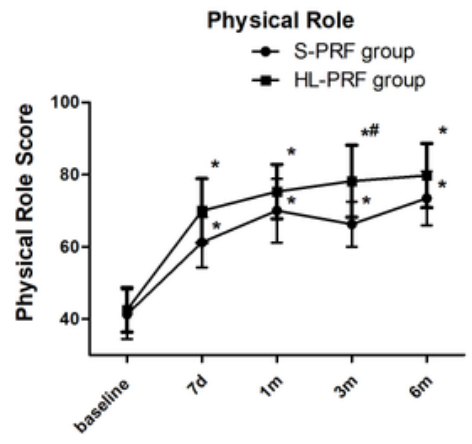

Social Function

$\rightarrow$ S-PRF group

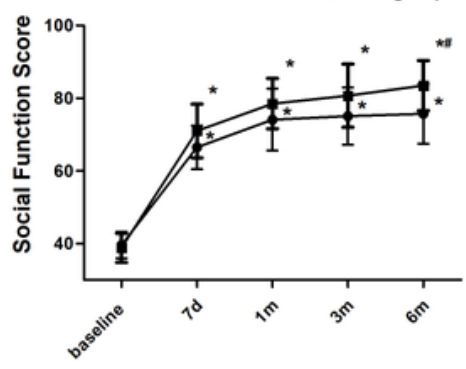

General Health

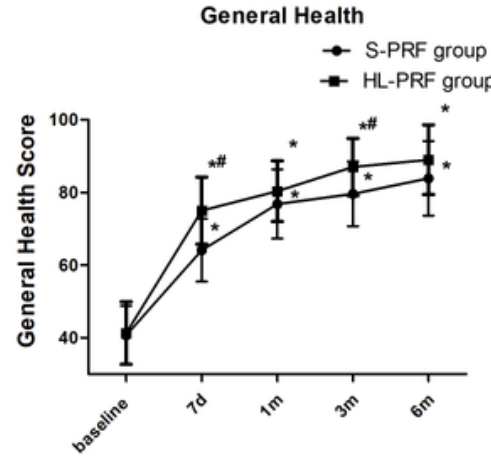

Physical Function

$\rightarrow$ S-PRF group

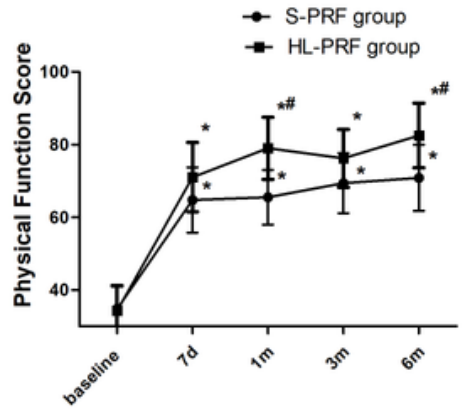

Role-emotional

$\rightarrow$ S-PRF group

$\rightarrow$ HL-PRF group

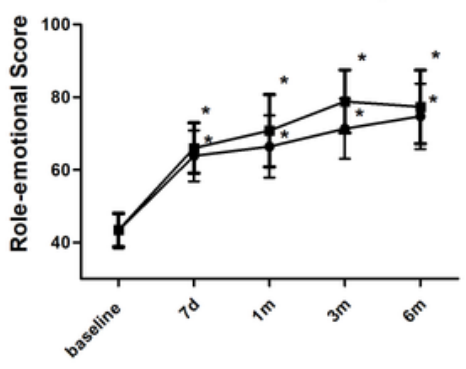

Vitality

$\rightarrow$ S-PRF group

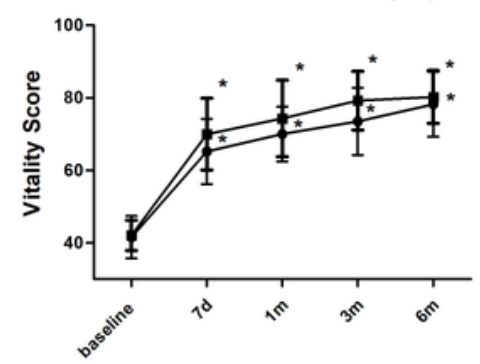

Figure 5

Significantly improved mean SF-36 scores after treatment ${ }^{*} \mathrm{p}<0.001$ indicates Pre VAS vs. Post VAS. $\# p<0.05$ indicates manual PRF group vs. auto PRF group. 


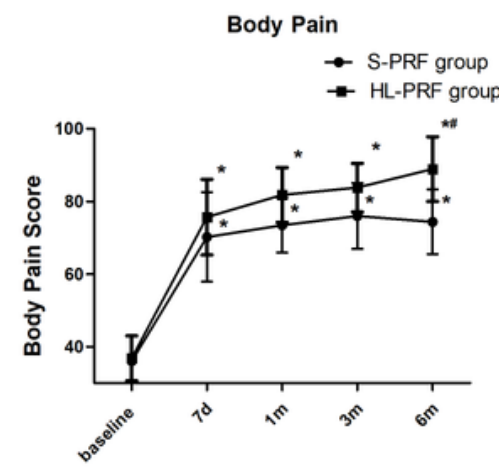

Mental Health

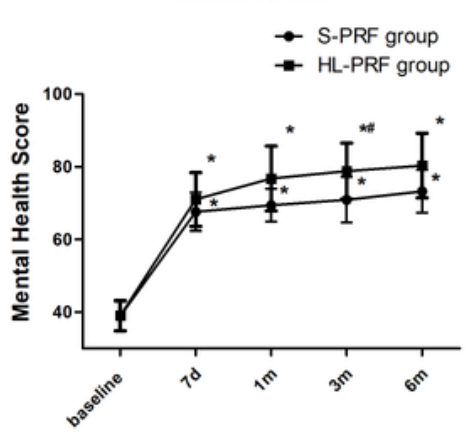

Physical Role

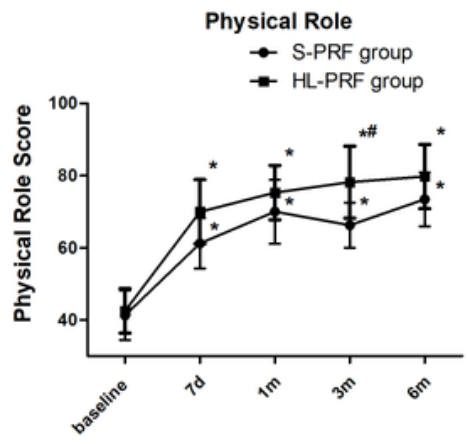

Social Function

$\rightarrow$ S-PRF group

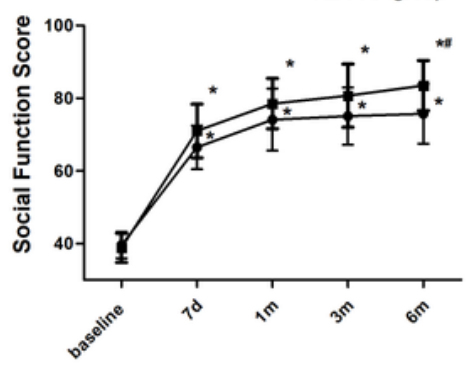

General Health

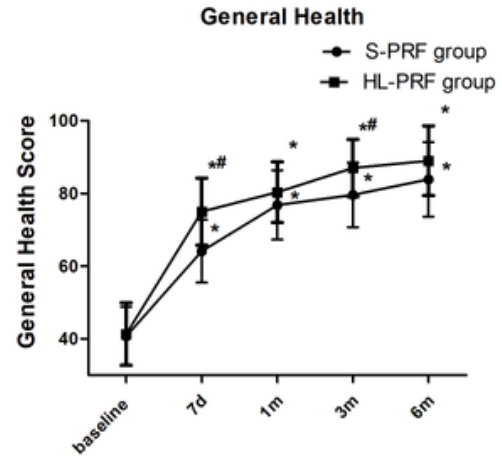

Physical Function

$\rightarrow$ S-PRF group

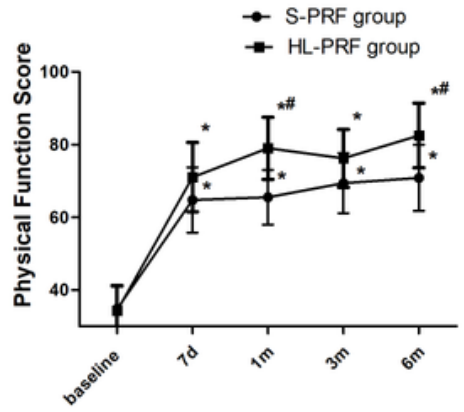

Role-emotional

$\rightarrow$ S-PRF group

- HL-PRF group

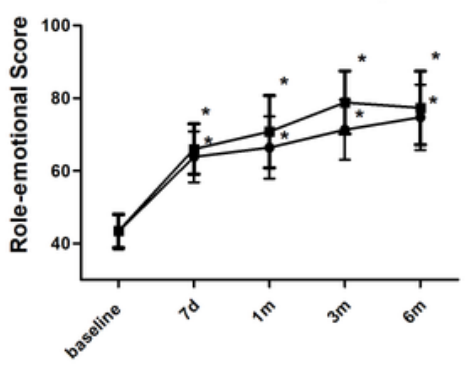

Vitality

$\rightarrow$ S-PRF group

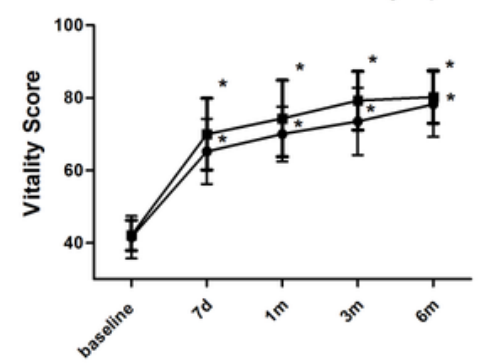

\section{Figure 5}

Significantly improved mean SF-36 scores after treatment * $p<0.001$ indicates Pre VAS vs. Post VAS. $\# p<0.05$ indicates manual PRF group vs. auto PRF group. 


\section{Pregabalin dosage(mg/d)}

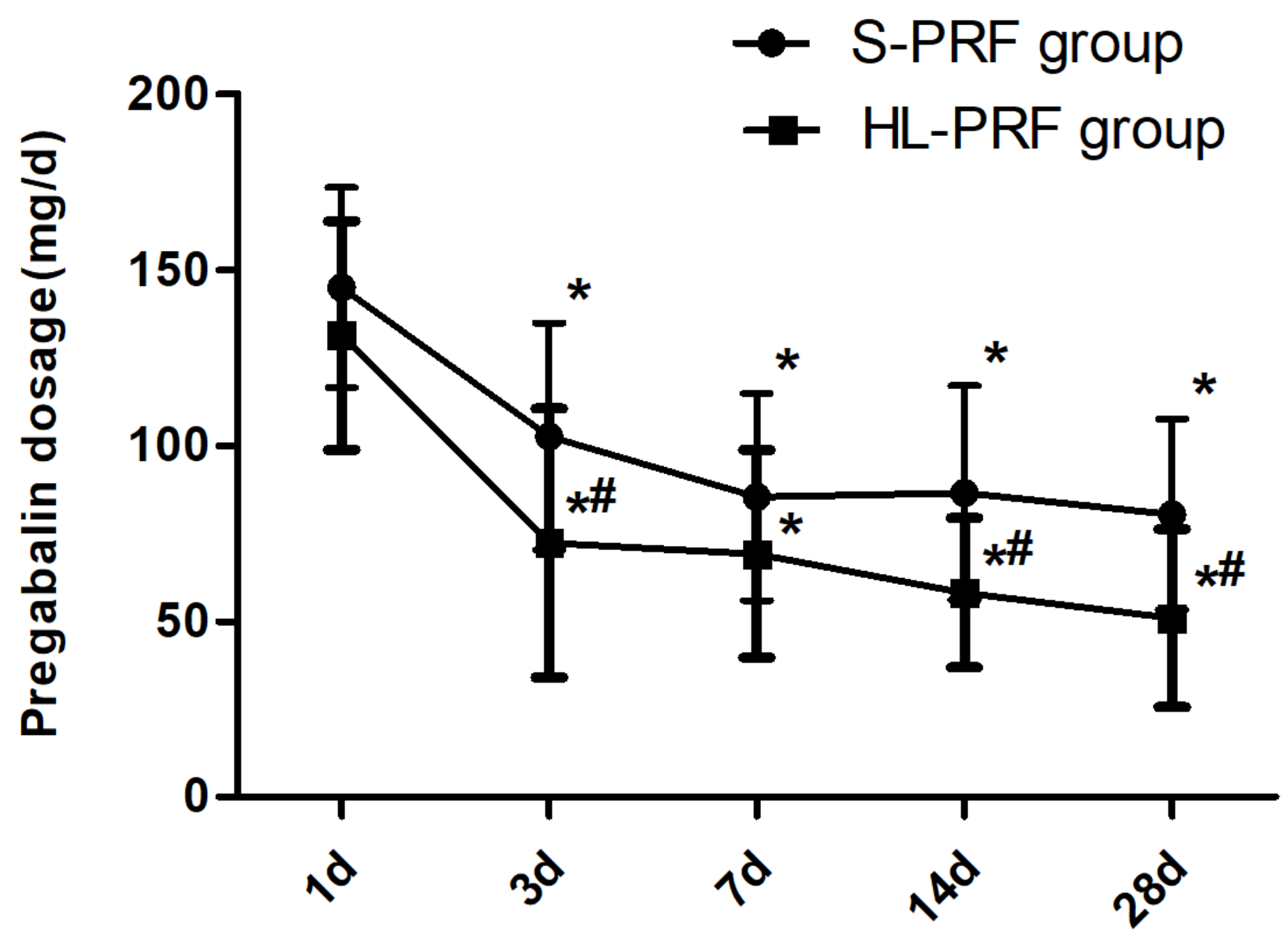

Figure 6

Significantly decreased mean dosages of pregabalin after treatment ${ }^{\star} p<0.001$ indicates Pre VAS vs. Post VAS. \#p<0.05 indicates manual PRF group vs. auto PRF group. 


\section{Pregabalin dosage(mg/d)}

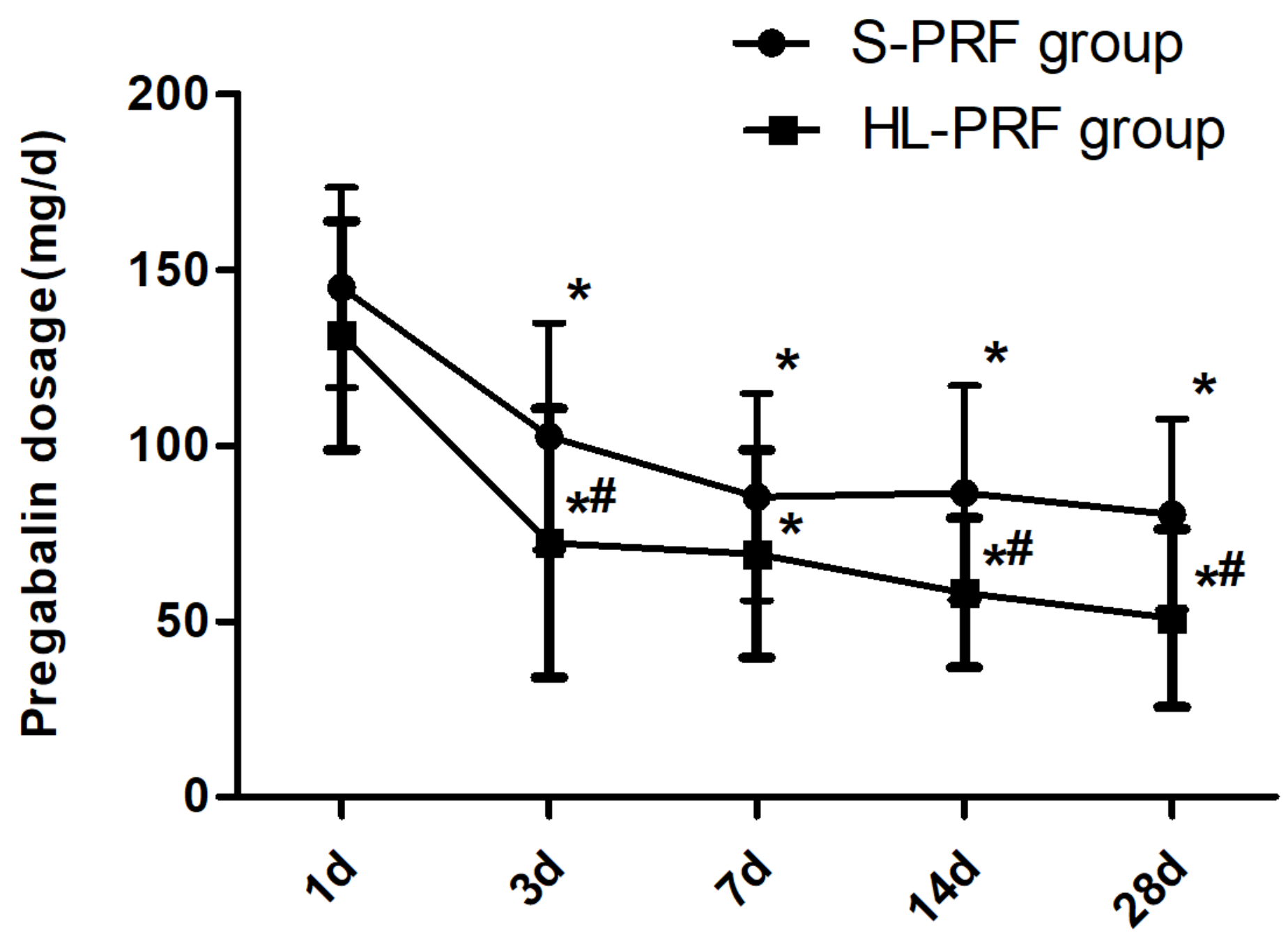

Figure 6

Significantly decreased mean dosages of pregabalin after treatment ${ }^{\star} p<0.001$ indicates Pre VAS vs. Post VAS. \#p<0.05 indicates manual PRF group vs. auto PRF group. 